\title{
Estimation of Infiltration Models' Parameters Using Regression Analysis in Irrigation Fields of Northern Ghana
}

\author{
Abdallah Salifu' ${ }^{1}$, Felix. K. Abagale ${ }^{2 *}$, Gordana Kranjac-Berisavljevic ${ }^{2}$ \\ ${ }^{1}$ Department of Agricultural Mechanisation and Irrigation Technology, Faculty of Agriculture, Food and Consumer Sciences, \\ University for Development Studies, Tamale, Ghana \\ ${ }^{2}$ West African Centre for Water, Irrigation and Sustainable Agriculture, University for Development Studies, Tamale, Ghana \\ Email: ^fabagale@uds.edu.gh
}

How to cite this paper: Salifu, A., Abagale, F.K. and Kranjac-Berisavljevic, G. (2021) Estimation of Infiltration Models' Parameters Using Regression Analysis in Irrigation Fields of Northern Ghana. Open Journal of Soil Science, 11, 164-176.

https://doi.org/10.4236/ojss.2021.113009

Received: February 6, 2021

Accepted: March 13, 2021

Published: March 16, 2021

Copyright $\odot 2021$ by author(s) and Scientific Research Publishing Inc. This work is licensed under the Creative Commons Attribution-NonCommercial International License (CC BY-NC 4.0). http://creativecommons.org/licenses/by-nc/4.0/

\begin{abstract}
The quantification of soil infiltration is necessary for the estimation of water accessibility in soils for plant growth and development. Field infiltration tests runs were conducted on agricultural soils in three irrigation sites of Northern Ghana. The field data were fitted into Green and Ampt, Kostiakov, Philip, Holtan, Soil Conservation Service and Horton infiltration models for the determination of the unknown model parameters. Regression analysis at $95 \%$ confidence level using GraphPad Prism 8. Laboratory and field data on infiltration were used for the model fitting and the unknown parameters were determined using the calibrated models. The $k$ and $n$ parameters of Kostiakov model at Bontanga study site were found to be $k=28.0027$ and $n=0.5902$, $k=17.0294$ and $n=0.4504$ for Golinga and $k=23.0356$ and $n=0.6339$ for Libga. For all the models, the coefficient of determination ranged from 0.7612 to 0.9876 indicating strong relationships. Only Holtan model gave different values at all the three study sites. The parameter GIa and $i_{c}$ of the Holtan model drawn from hydrologic soil group were the same at all the study sites because of the same vegetative cover and surface conditions. The study observed the values of the parameters to have influenced the models' performance.
\end{abstract}

\section{Keywords}

Parameter, Infiltration Model, Regression, Sorptivity, Transmissivity

\section{Introduction}

It is necessary to quantify infiltration in order to estimate the accessibility of wa- 
ter for plant growth and to determine the volume of extra water required for irrigation [1]. For this study, field infiltration data were fitted into some models for the determination of unknown model parameters. Six (6) infiltration models were used in the parameter estimation using data from the field and in the laboratory. These models are Green and Ampt (1911), Kostiakov (1932), Horton (1940), Philip (1954), Holtan (1961) and USDA (1972).

The infiltration models that can properly predict infiltration rates are paramount for determination of behaviour of water in soil and water management activities. The challenge in predicting infiltration is mainly because of the variation of infiltration-related soil physical properties from a different site in the field indirectly influencing the model's parameters. In order to simplify infiltration predictions, several researchers [2] and [7] introduced simple time-dependent algebraic equations.

Numerous models that make the concept of infiltration an easy process have been established for field use. The data from the field experiment are usually processed and fitted into the models to determine numerical values of the model's parameters and to appraise the applicability of the infiltration models in the soil or site. These parameters are influenced by soil texture, moisture content, soil bulk density, and other soil properties and are site-specific [8].

Truly based approximation equations use obtainable parameters which acquisition from soil water properties is likely and do not need estimated infiltration information.

Different equations are somewhat or completely exact and boundaries should be gotten from estimated infiltration information or generally assessed by different methods. Empirical equations, for example, Kostiakov and Horton are not much prohibitive to the method of water usage since they do not need the suppositions with respect to soil surface and profile conditions that the truly based conditions need [9].

Where soils are diverse, and features, for example, large pore size stream and ensnared air entangle the water penetration processes, empirical equations might possibly give better predictions, once they are utilized by considering comparative settings aided in their establishment. Fundamentally, the grounds that their underlying boundaries are resolved dependent on real field-estimated infiltration information [10] [11] [12].

All the infiltration models use soil boundaries, for example, sorptivity/initial infiltration, pressure driven conductivity, and volumetric water content. They likewise utilize the soil water retention-curve; which esteems are characterized by alignment fit or estimations. These boundaries have vulnerability, brought about by mistakes in information assortment from field or research facility, imprecision or mistaken alignment hardware and spatial and transient varieties.

Numerous penetration models have been created to foresee infiltration rate as a component of time and physical or empirical boundaries, for an alternate sort of soils. Every one of these models is appropriate to specific parameters and the 
parameters feeding these models have operational challenges. These challenges become significant relying upon the affectability of them to the rate of infiltration [13].

Kostiakov's infiltration model's parameters such as the values of empirical constant " $c$ " were found in the range of $0.140-0.290$ and the values of infiltration decay constants " $\beta$ " were attained in the range of $0.307-0.433$. The values of infiltration decay constant " $\beta$ " were in harmony with the theory of infiltration that defined the values to be positive and always less than unity. It has also been reported that most values of these parameters lie between $0.2-0.9$. The Philip's infiltration model parameters such as sorptivity " $S$ " values were found in the range of $0.167-0.288 \mathrm{~cm} / \mathrm{min}$ and conductivity constant " $A$ " values were obtained as -0.001 to $-0.009 \mathrm{~cm} / \mathrm{min}$ for all the six points. [14] Described the high variability of these parameters along the top sequence. Similarly, Horton's model's parameters such as constant " $\beta$ " was determined and in the range of -1.619 to -1.238 . The estimated values of these infiltration models' parameters can be used for developing the infiltration equation for the study area after verification [8].

The study estimated parameters of six (6) soil infiltration models that are commonly used in the prediction of infiltration of agricultural soils.

\section{Materials and Methods}

\subsection{Description of the Study Area}

The study was conducted at Bontanga, Golinga and Libga irrigation sites in the Northern Region of Ghana.

Bontanga Irrigation Scheme is located at Bontanga in the Kumbungu District, $34 \mathrm{~km}$ Northwest of Tamale. It lies between latitude $9^{\circ} 57^{\prime} \mathrm{N}$ and longitude $1^{\circ} 02^{\prime} \mathrm{W}$.

The Golinga Irrigation Scheme is situated in the Tolon District of the Northern Region of Ghana and it lies on latitude $9^{\circ} 4^{\prime} \mathrm{N}$ and longitude $1^{\circ} 0^{\prime} \mathrm{W}$.

The Libga Irrigation Scheme is located in the Savelugu Municipality in the Northern Region of Ghana. It lies between latitude $9^{\circ} 59^{\prime} \mathrm{N}$ and longitude $0^{\circ} 85^{\prime} \mathrm{W}$ [15].

Crops usually cultivated at the irrigation schemes are Rice (Oryza sativa), Onion (Allium cepa), Roselle (Hibiscus sabdariffa), Maize (Zea mays), Okra (Hibiscus esculentus), Tomato (Lycopersicon esculentum) Pepper (Capsicum frutescens), Vegetable jute (Corchorus olitorius), Garden eggs (Solanum melongena), Groundnut (Arachis hypogea), Cowpea (Vigna unguiculata), Amaranth, "Alefu" (Amaranthus spinosus) [16].

\subsection{Data Sources}

Data was obtained from field and laboratory work. For data collection of the study, undisturbed samples of soil were collected from the field to determine the hydraulic conductivity and, gravimetric water content in the laboratory whilst 
soil infiltration test was carried out using double ring infiltrometer in the field.

\subsection{Model Calibration and Parameter Determination}

Calibration or adjustment is the iterative process of contrasting the model and genuine framework, changing the model if essential, re-examining it, until a model is acknowledged or accepted.

The need to estimate the models' parameters was to create the basis upon which the sensitivity of the models' parameters and their predictions of the infiltration rates could be determined and to also ease the comparisons between predicted and observed infiltration rates.

The infiltration curves from Libga, Bontanga and Golinga irrigation sites, were used to adjust the empirical Kostiakov, SCS and Horton Models. Infiltration curve parameters for Kostiakov, Horton and SCS models were obtained from Equations (2), (4) and (16) using logarithmic and semi-logarithmic methods.

Philip and Green-Ampt models' parameters were found using regression analysis. Parameters for the Holtan equation were gotten from estimated starting and saturated moisture contents and from organized standards conforming to the soil state and the nature of vegetation characterizing the study locations [12].

\subsection{Kostiakov Equation}

The two (2) empirical constants $k$ and $n$ of the Kostiakov model were obtained using Equation (2).

The gradient and intercept of the linear equation were found with a plot of lo$\mathrm{g} I$ verse $\log t[17]$ and $\log k$ of the equation was the intercept and the slope was $n$.

$$
I=k t^{n}
$$

That is;

$$
\log I=\log k-n \log t
$$

If the value of $n$ is higher, the slope is steeper and the larger the rate of decay of infiltration. The bigger the value of $k$, the bigger the initial infiltration value [12] [18].

\subsection{Horton Equation}

Horton [4] equation for infiltration rate $(i)$ is:

$$
i=i_{c}+\left(i_{o}-i_{c}\right) \mathrm{e}^{-\beta t}
$$

where: $i_{c}$-the continuous infiltration capacity as time gets to infinity; $i_{o}$-infiltration capacity at the beginning of water penetration; and $\beta$-the positive persistent dependent on soil and introductory conditions of water.

The parameter $i_{c}$ was found from the infiltration curve whilst $i_{o}$ was deduced from the experimental values for $i$ and the common log of the outcome plotted as time dependent. $\beta$ was determined from the gradient of the line and $i_{o}$ from the intercept. The base value for parameter $\beta$ was equivalent to the negative gra- 
dient, and the start of infiltration capacity, $i_{o}$ was determined using Equation (4).

$$
\ln \left(i-i_{c}\right)=\ln \left(i_{o}-i_{c}\right)-\beta t
$$

Parameters $i_{\phi} i_{c}$ and $k$ were obtained by plotting $\ln \left(i-i_{c}\right)$ against $t$.

\subsection{Holtan Equation}

The Holtan equation parameters are; $G I$, $a$, and $i_{c}$ Based on the site location, the average values for $a$, were gotten from hydrologic group [12] [19] as presented in Table 1 . The values of the steady infiltration $\left(i_{c}\right)$ were obtained from soil hydrologic group built on values founded by [20]. $G I$ was estimated by considering the age-long existence of ground cover and with available storage determined from the moisture deficit using Equation (5);

$$
M_{i}=\theta_{s}-\theta_{i}
$$

The average moisture deficit $\left(M_{i}\right)$ of the control depth, multiplied by the assessed depth gave available storage. Holtan and Lopez [21] indicated that after some number of adjustments, the resulting equation is Equation (6);

$$
i_{p}=\operatorname{GIaSA}^{1.4}+i_{c}
$$

where: $i_{p}$-infiltration rate $\left(\mathrm{Lt}^{-1}\right), S A$-available storage (L), $G I$-growth index of crop in percent of maturity, a-an index of surface connected porosity (in.hr. ${ }^{-1}$ per (in. $)^{1.4}$ of storage), $i_{c}$-steady state infiltration rate $\left[\mathrm{Lt}^{-1}\right]$.

$S A$ was calculated using Equations (7) or (8):

$$
\begin{gathered}
S A=\left(\theta_{s}-\theta_{i}\right) d \\
S A=M_{i} \times d
\end{gathered}
$$

\begin{tabular}{|c|c|c|c|c|c|}
\hline \multirow{2}{*}{ Model Name } & \multirow{2}{*}{ Model Equation } & \multirow{2}{*}{ Parameters } & \multicolumn{3}{|c|}{ Estimated Parameter Value } \\
\hline & & & Bontanga & Golinga & Libga \\
\hline Kostiakov & $I=K t^{n}$ & $K$ and $n$ & $\begin{array}{c}K=28.0027 \\
n=0.5902\end{array}$ & $\begin{array}{c}K=17.0294 \\
n=0.4504\end{array}$ & $\begin{array}{c}K=23.0356 \\
n=0.6339\end{array}$ \\
\hline Philip & $I=S t^{0.5}+A t$ & $S$ and $A$ & $\begin{array}{c}S=49.778 \\
A=-11.254\end{array}$ & $\begin{array}{c}S=41.858 \\
A=-14.163\end{array}$ & $\begin{array}{c}S=33.25 \\
A=-2.3953\end{array}$ \\
\hline Horton & $I=i_{c} t+\frac{i_{o}-i_{c}}{k}\left[1-\mathrm{e}^{-k t}\right]$ & $i_{o}, i_{c}$ and $k$ & $\begin{array}{c}i_{0}=73.4417 \\
i_{c}=2.66 \\
k=1.9794\end{array}$ & $\begin{array}{c}i_{0}=45.6589 \\
i_{c}=0.4 \\
k=1.8578\end{array}$ & $\begin{array}{c}i_{0}=46.2287 \\
i_{c}=5 \\
k=1.6332\end{array}$ \\
\hline Green and Ampt & $I=X+Y / I$ & $X$ and $Y$ & $\begin{array}{l}X=3.325 \\
Y=395.16\end{array}$ & $\begin{array}{c}X=-11.683 \\
Y=341.33\end{array}$ & $\begin{array}{c}X=-6.3031 \\
Y=210.08\end{array}$ \\
\hline Holtan & $I=\operatorname{GIaSA}^{1.4}+i_{c}$ & $G I$, a and $i_{c}$ & $\begin{array}{c}G I=0.3 \\
a=1.0 \\
i_{c}=7.6\end{array}$ & $\begin{aligned} G I & =0.3 \\
A & =1.0 \\
i_{\mathcal{C}} & =7.6\end{aligned}$ & $\begin{array}{c}G I=0.3 \\
A=1.0 \\
i_{c}=7.6\end{array}$ \\
\hline SCS & $I=c t^{d}+0.6985$ & $c$ and $d$ & $\begin{array}{c}c=40.0867 \\
d=0.5902\end{array}$ & $\begin{array}{c}c=24.3837 \\
d=0.4504\end{array}$ & $\begin{array}{c}c=32.9761 \\
d=0.6339\end{array}$ \\
\hline
\end{tabular}

where: $\theta_{s}$-saturated soil water content $\left(\mathrm{L}^{3} \mathrm{~L}^{-3}\right), \theta_{i}$-volumetric soil water

Table 1. Estimated infiltration model parameters. 
Content $\left(\mathrm{L}^{3} \mathrm{~L}^{-3}\right)$ and $d$-depth of the sampled soil from the surface layer $(L)$.

\subsection{Philip Equation}

Cumulative infiltration, for Philip's model is described using Equation (9):

$$
I=S t^{0.5}+A t
$$

where; $I$-cumulative infiltration (L), $S$-sorptivity $\left(\mathrm{LT}^{1 / 2}\right), t$-time of infiltration $(\mathrm{T})$ and

$A$-parameter is known as transmissivity $\left(\mathrm{LT}^{-1}\right)$.

The infiltration rate was established by differentiating Equation (10).

$$
\mathrm{d} I / \mathrm{d} t=i(t)=0.5 S t^{-0.5}+A
$$

Parameters $A$ and $S$ were estimated by plotting the graph of $i$ against $t^{0.5}$ and compared with straight line equation gives $A$ as intercept and $S$ as slope or gradient.

\subsection{Green-Ampt Equation}

Green and Ampt recommended an equation for infiltration rate developed from Darcy's law as in Equation (11) [22].

$$
i=K\left(1+\frac{\mu S_{c}}{I}\right)
$$

where: $\mu$-soil porosity, $S_{c}$-capillary suction at the wetting front, and $K$-hydraulic conductivity.

Equation (11) can be re-written as Equations (12) or (13):

$$
\begin{gathered}
i=X\left(1+\frac{y}{x I}\right) \\
i=x+\frac{y}{I}
\end{gathered}
$$

where: $x$ and $y$ are parameter values for Green and Ampt model obtained by plotting a graph of $i$ against $1 / I$ and drawing the best fit lines, where $y$ equals to gradient and $x$ equals to intercept of $i$-axis. Cumulative $(I)$ values were used to predict $i$ values using Equation (13).

\subsection{USDA Soil Conservation Service (SCS) Model}

The USDA SCS model has been described by [23] and [24] as one of the empirically developed approaches to water infiltration and is written as Equation (14).

$$
I=c t^{d}+0.6985
$$

where: $I$-cumulative infiltration rate, $c$ and $d$-constants.

The constants $c$ and $d$ were determined from observed infiltration data by taking logarithm to both sides of Equation (14) to give Equation (15), and $\log I$ was plotted against $\log t$ and the equation was compared to linear equation to determine the parameter $c$ and $d$. 


$$
\log I=\log C+\log 0.6985+d \log t
$$

\subsection{Data Analysis}

Linear regression analysis was undertaken at 95\% confidence level whilst Graph Pad Prism 8 was used for the data analysis and Microsoft Excel 10 was used for plotting of graphs.

\section{Results and Discussion}

\subsection{Estimated Infiltration Model Parameters}

The model parameters as base values of the various infiltration models are presented in Table 1. Model parameters are very important in predicting the infiltration characteristics of a typical soil condition.

These base values were obtained using fittings of the models constructed from the experimental data with the exception of Holtan model parameters, whose values were obtained from soil hydrologic group. The parameters of the models determined were used to calculate the condition numbers and subsequently test the degree of sensitivity of each model to change in model parameters. The values of the parameters were also used for prediction of models' infiltration rates.

\subsection{Kostiakov Infiltration Model Parameters}

The model parameters of the Kostiakov model at the Bontanga irrigation scheme were $k=28.0027$ and $n=0.5902, k=17.0294$ and $n=0.4504$ for Golinga and $k=$ 23.0356 and $n=0.6339$ for Libga irrigation scheme using fittings of Kostiakov Equation (15).

[25] at Hisar and Kurukshetra districts of Haryana, India reported Kostiakov parameters, $k=23.56$ and 18.32; and $n=0.69$ and 0.36 and noted to be lower than the $k$ and $n$ values obtained at Bontanga, but similar to values reported at Golinga and Libga study sites. Literature reveals that $k$ is consistently $\geq 1$ and $n$ is consistently $\leq 1$.

The fitting of the model to the infiltration data yielded coefficient of determination of 0.9702 at Bontanga, 0.9565 at Golinga and 0.9876 at Libga study sites as in Figure 1. These indicate good correlation between the observed infiltration and the modeled infiltration, since high values of the coefficient of determination $>95 \%$ indicates a good relationship.

[9] proved that the value of $n$ parameter in the Kostiakov equation can be more than unity as oppose to the general opinion that $n$ parameter is found between zero and one. [26], however, found analytically that the value of $n$ was constantly less than one and this was found to be consistent with the findings in this study [12].

\subsection{Horton Infiltration Model Parameters}

Plots of in $\left(i_{o}-i_{c}\right)$ against time using Equation (4), aided determination of the parameters of the model using constant infiltration rate of $i_{c}=2.66 \mathrm{~mm} / \mathrm{h}$. At 


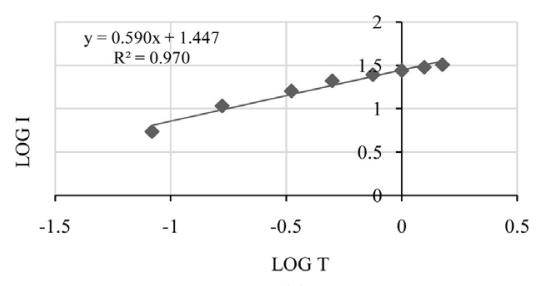

(a)

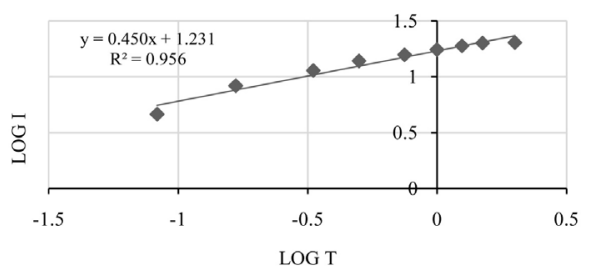

(b)

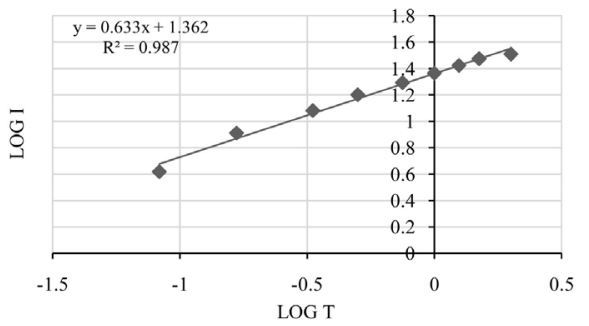

(c)

Figure 1. Kostiakov infiltration model fitting for the study sites. (a) Bontanga; (b) Golinga; (c) Libga.

Bontanga, the $i_{o}$ parameter was $73.4417 \mathrm{~mm} / \mathrm{h}$ and the infiltration decay rate $(\beta)=1.9794 \mathrm{~mm} / \mathrm{h}$; whilst at Golinga, the $i_{o}$ was $45.6589 \mathrm{~mm} / \mathrm{h}$ and the infiltration decay rate $(\beta)=1.8578 \mathrm{~mm} / \mathrm{h}$ and $i_{c}=0.4 \mathrm{~mm} / \mathrm{h}$ and with Libga recording $i_{o}$ of $46.2287 \mathrm{~mm} / \mathrm{h}, \beta=1.6332 \mathrm{~mm} / \mathrm{h}$ and $i_{c}=5 \mathrm{~mm} / \mathrm{h}$.

The model fitting to the infiltration data yielded coefficient of determination of 0.9602 at Bontanga, 0.9404 at Golinga and 0.8781 at Libga as presented in Figure 2. The coefficient of variation of the three (3) sites presents a good relationship between the measured and modeled infiltration.

\subsection{Philip Infiltration Model Parameters}

Plots of $i \mathrm{~mm} / \mathrm{h}$ against $t^{0.5}(\mathrm{~h})$ from which sorptivity $(S)$ of 49.778 and transmissivity $(A)$ of $-11.254 \mathrm{~mm} / \mathrm{h}$ were obtained at the Bontanga study site; $S=$ 41.858 and $A=-14.163 \mathrm{~mm} / \mathrm{h}$ at Golinga study site and $S=33.25$ and $A=$ $-2.3953 \mathrm{~mm} / \mathrm{h}$ at Libga sites were obtained as the model parameters Figure 3 . Fitting the model to the infiltration data yielded coefficient of determination of 0.9177, 0.9714 and 0.917 for the Bontanga, Golinga and Libga study sites respectively. The coefficient of determination indicates a very good relationship between field and modeled infiltration data of the study sites.

Negative values, for assessed transmissivity, indicate extra infiltration took place and/or exudation of water from the ground was realized as noted by [27] [28]. However, it has been noted to be impossible to interpret the negative value for transmissivity physically. Sites with high negative transmissivity e.g. Bontanga $(-11.254 \mathrm{~mm} / \mathrm{h})$ and Golinga $(-14.123 \mathrm{~mm} / \mathrm{h})$ recorded lower infiltration rates of $0.64 \mathrm{~mm} / \mathrm{h}$ by the models' prediction as compared to infiltration rates of $9.36 \mathrm{~mm} / \mathrm{h}$ at Libga with $-2.3953 \mathrm{~mm} / \mathrm{h}$ transmissivity.

\subsection{Green and Ampt Infiltration Model Parameters}

Green-Ampt model parameters $X$ and $Y$ obtained for the various study sites 


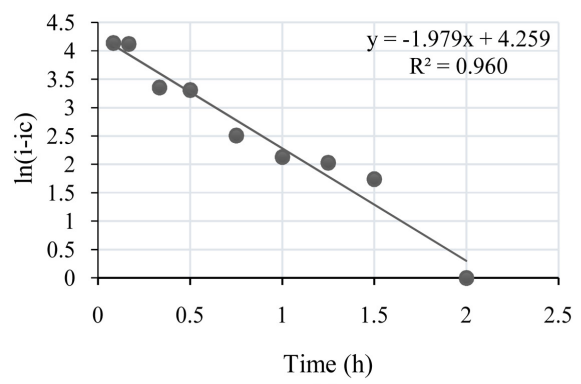

(a)

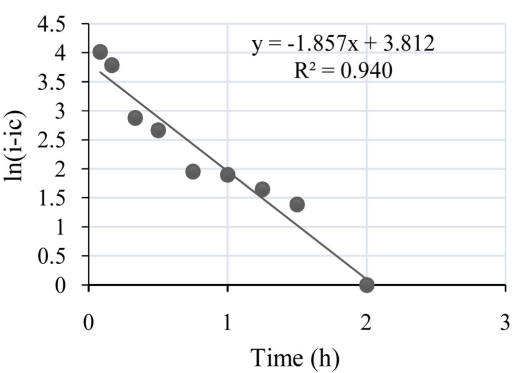

(b)

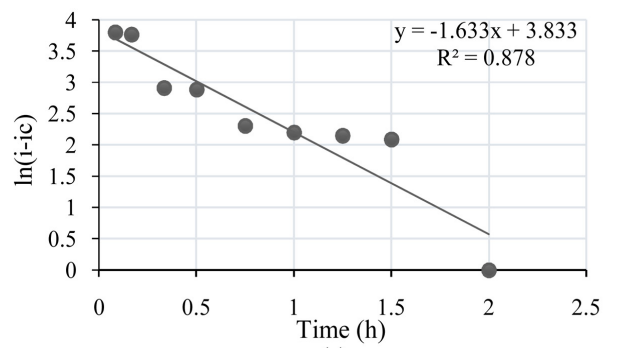

(c)

Figure 2. Horton infiltration model fitting for the study sites. (a) Bontanga; (b) Golinga; (c) Libga.

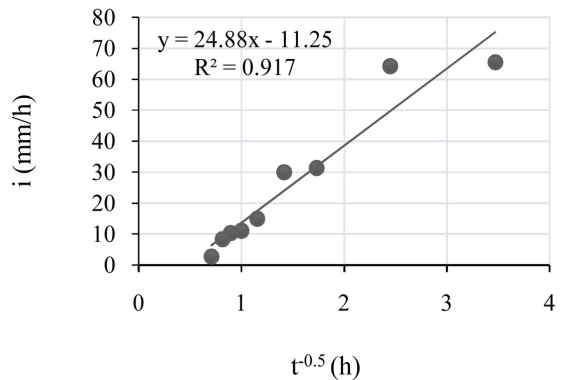

(a)

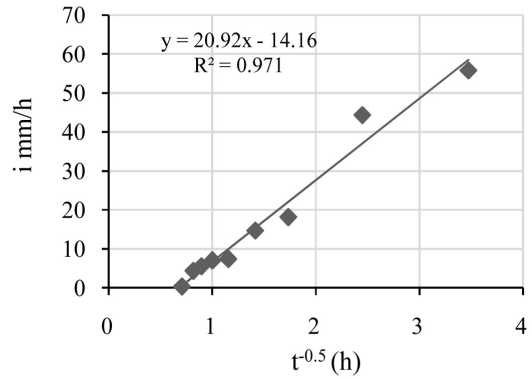

(b)

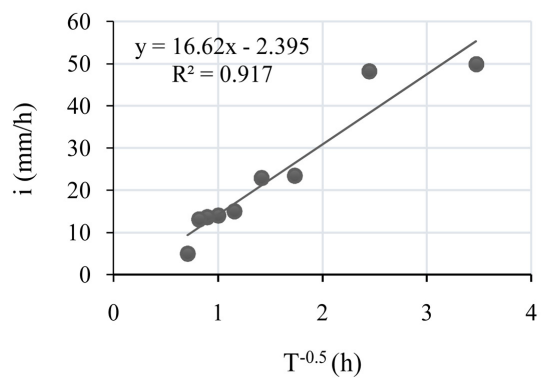

(c)

Figure 3. Philip infiltration model fitting for the study sites. (a) Bontanga; (b) Golinga; (c) Libga.

were $X=3.325 \mathrm{~mm} / \mathrm{h}$ and $Y=395.16 \mathrm{~mm} / \mathrm{h}$ at Bontanga; $X=-11.683 \mathrm{~mm} / \mathrm{h}$ and $Y=341.33 \mathrm{~mm} / \mathrm{h}$ at Golinga and $X=6.303 \mathrm{~mm} / \mathrm{h}$ and $Y=210.08$ at Libga. The fitting of the model to the infiltration data yielded coefficient of determination of 0.7612 at Bontanga, 0.9007 at Golinga and 0.8068 at Libga study sites as presented in Figure 4. These values indicate a good correlation between the observed infiltration values and the model infiltration values. What these values tell 


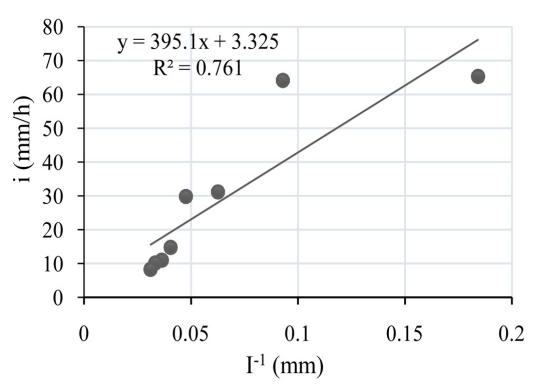

(a)

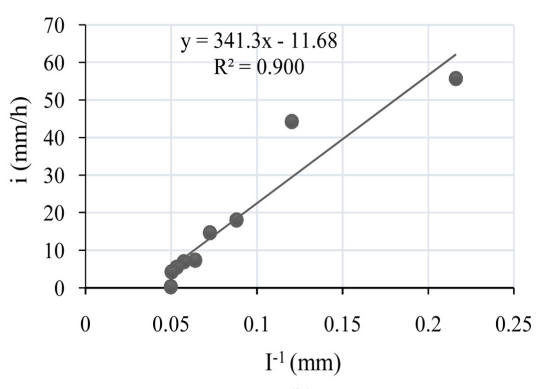

(b)

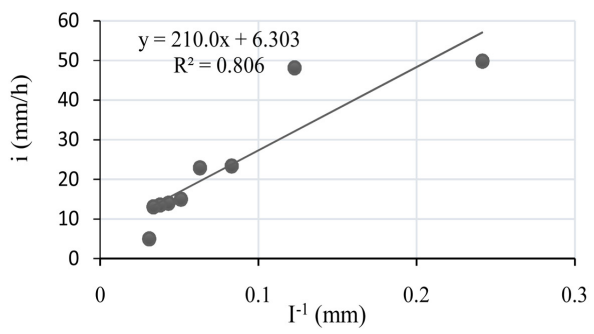

(c)

Figure 4. Green and ampt infiltration model fitting for the study sites. (a) Bontanga; (b) Golinga; (c) Libga.

us is that the model relates better to the infiltration rates data at Golinga than to the infiltration rates at Bontanga and Libga.

These values reflect the prediction ability of the model. Considering Libga and Golinga, the direct association between $i, X, Y$ and $I^{-1}$ was observed. Comparing Equation (20) to Equation (21) indicates that $\mathrm{Y}$ represents physical and hydraulic parameters such as porosity, suction front and hydraulic conductivity. Therefore, increasing these parameters will increase the infiltration rates and vice versa. These parameters were used in Green and Ampt model prediction and determination of the sensitivity of the model to change in its parameter values at the Bontanga study site.

\subsection{Soil Conservation Service (SCS) Infiltration Model Parameters}

The SCS model parameters $c$ and $d$ obtained through plots of infiltration data were, $c=40.0867 \mathrm{~mm} / \mathrm{h}$ and $d=0.5902 \mathrm{~mm} / \mathrm{h}$ for Bontanga; $c=24.3837 \mathrm{~mm} / \mathrm{h}$ and $d=0.4504 \mathrm{~mm} / \mathrm{h}$ for Golinga and $c=32.9761 \mathrm{~mm} / \mathrm{h}$ and $d=0.6339 \mathrm{~mm} / \mathrm{h}$ for Libga study sites. These parameters were used to predict the models' infiltration rates and also undertake the model sensitivity analysis. Fitting the model to the infiltration data yielded coefficient of determination of 0.9702 at Bontanga, 0.9565 at Golinga and 0.9876 at Libga as presented in Figure 5. These values indicate an excellent relationship between observed infiltration and modeled infiltration values.

[25] in a similar study obtained $c=48.39$ and $d=0.62 ; c=34.15$ and $d=0.76$ at Hisar and Kurukshetra districts of Haryana, India. These values conform with the values obtained in this study on the basis established by [28] that $c>0$ and $0<d<1$. 


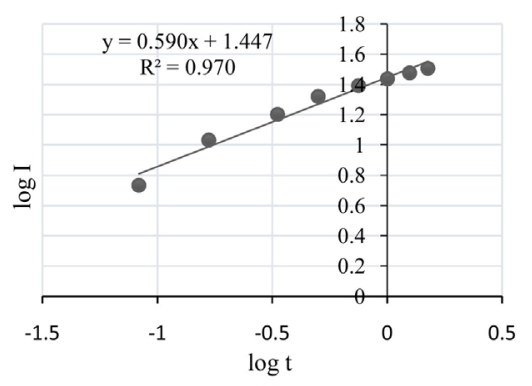

(a)

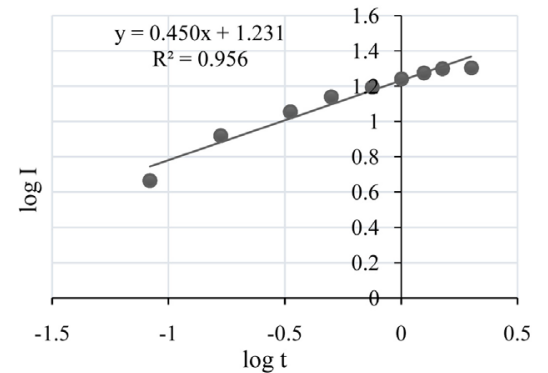

(b)

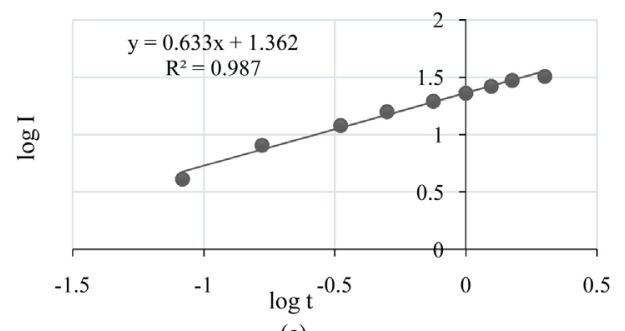

(c)

Figure 5. SCS infiltration model fitting for the study sites. (a) Bontanga; (b) Golinga; (c) Libga.

\section{Conclusion}

Each model's parameters for all the six (6) models except Holtan model gave different values at all the three study sites. The parameter GIa and $i_{\mathcal{C}}$ of Holtan model drawn from hydrologic soil group, were the same at all the study sites because of the similar vegetative cover and surface conditions. The values of the parameters influenced the models' performance. For all the models, the coefficient of determination indicated good relationships and with the parameter values also influencing models' performance.

\section{Acknowledgements}

The findings of this paper are part of a Ph.D. thesis and the authors are grateful to the staff and students of the Department of Agricultural Mechanisation and Irrigation Technology, Faculty of Agriculture, Food and Consumer Sciences, University for Development Studies, Ghana. Also, field data collection for this work was supported by Staff and Farmers of the Botanga, Goling and Libga Irrigation Projects. This support is therefore very much appreciated by the authors.

\section{Conflicts of Interest}

The authors declare that they have no competing interest regarding this publication.

\section{References}

[1] Tuffour, O. (2015) Physically based Modeling of Water Infiltration with Soil Particle Phase. Ph.D. Thesis, Kwame Nkrumah University of Science and Technology, Kumasi.

[2] Green, W.H. and Ampt, G.A. (1911) Studies in Soil Physics. The Journal of Agri- 
cultural Science, 4, 1-24. https://doi.org/10.1017/S0021859600001441

[3] Kostiakov, A.N. (1932) On the Dynamics of the Confinement of Water Percolation in Soils and on the Necessity of Studying It from a Dynamic Point of View for Purpose of Amelioration. Society of Soil Science, 14, 17-21.

[4] Horton, R.E. (1941) An Approach toward a Physical Interpretation of Infiltration Capacity. Soil Science Society of America Journal, 5, 399-417. https://doi.org/10.2136/sssaj1941.036159950005000C0075x

[5] Philip, J.R. (1954) An Infiltration Equation with Physical Significance. Soil Science, 77, 153-158. https://doi.org/10.1097/00010694-195402000-00009

[6] Holtan, H.N. (1961) A Concept for Infiltration Estimates in Watershed Engineering. Agricultural Research Service, United States Department of Agriculture, USA, 41-51.

[7] USDA Soil Conservation Service (1972) National Engineering Handbook, Section 4, Hydrology. USDA Soil Conservation Service, Washington DC. USDA-ARS Tech. Bull. No. 1435, Agricultural Research Station, Beltsville, Md.

[8] Farid, H.U., Mahmood-Khan, Z., Ahmad, I., Shakoor, A., Anjum, M.N., Iqbal, M. M., Mubeen, M. and Asghar, M. (2019) Estimation of Infiltration Models Parameters and their Comparison to Simulate the Onsite Soil Infiltration Characteristics. International Journal of Agricultural and Biological Engineering, 12, 84-91. https://doi.org/10.25165/j.ijabe.20191203.4015

[9] Hillel, D. (1998) Environmental Soil Physics. Academic Press, San Diego, CA.

[10] Rawls, W.J., Brakensiek, D.L. and Shirmohammadi, A. (1993) Infiltration and Soil Water Movement. In: Maidment, D.R., Ed., Handbook of Hydrology, McGraw-Hill, New York, USA.

[11] Skaggs, R.W. and Khaleel, R. (1982) Hydrologic Modeling of Small Watersheds. In: Haan, C.T., Johnson, H.P. and Brakenstek, D.L., Eds., An ASAE Monograph Number 5 in a Series, American Society of Agricultural Engineers, USA.

[12] Turner, E.R. (2006) Comparison of Infiltration Equations and Their Field Validation with Rainfall Simulation. M.Sc. Thesis, University of Maryland, College Park, Maryland.

[13] Estefanía, M.H. and André, L.B.C. (2015) Sensitivity Analysis of One-Dimensional Infiltration Models. Electronic Journal of Geotechnical Engineering, 20, 4313-4324.

[14] Azuka, C.V., Mbagwu, J.S.C. and Oyerinde, G.T. (2013) Infiltration Characteristics and Their Prediction on a Toposequence at Nsukka, South-Eastern Nigeria. International Journal of Science and Advanced Technology, 3, 1-7.

[15] Adongo, T.A., Kyei-Baffour, N., Abagale F.K. and. Agyare, W.A. (2019) Assessment of Reservoir Sedimentation of Irrigation Dams in Northern Ghana. Lake and Reservoir Management, 36, 87-105. https://doi.org/10.1080/10402381.2019.1659461

[16] Ghana Irrigation Development Authority (2017) Factsheet of Ghana Irrigation Authority. Ghana Irrigation Development Authority, Ghana.

[17] Criddle, W.D., Davis, S., Pair, C.H. and Shockley, D.G. (1956) Methods for Evaluating Irrigation Systems. Soil Conservation Service, United States Department of Agriculture, USA, $24 \mathrm{p}$.

[18] Naeth, M.A., Chanasyk, D.S. and Bailey, A.W. (1991) Applicability of the Kostiakov Equation to Mixed Prairie and Fescue Grasslands of Alberta. Journal of Range Management, 44, 18-21.

[19] Frere, M.H., Onstad, C.A. and Holtan, H.N. (1975) ACTMO, An Agricultural 
Chemical Transport Model. ARS-H-3, Agricultural Research Service, US Department of Agriculture, Washington DC, 54.

[20] Musgrave, G.W. (1955) How Much of the Rain Enters the Soil? In: The United States Department of Agriculture, Ed., Water: Year book of Agriculture, The United States Department of Agriculture, Washington DC, 151-159.

[21] Holtan, H.N. and Lopez, N.C. (1971) USDAHL-70 Model of Watershed Hydrology. Technical Bulletins from United States Department of Agriculture, Economic Research Service, Article No. 171863.

[22] Subramanya, K. (2008) Engineering Hydrology. 3rd Edition, Tata McGraw-Hill Publishing Company Limited, New Delhi.

[23] Jury, W.A., Gardner, W.R. and Gardner, W.H. (1991) Soil Physics. 5th Edition. John Wiley \& Sons, New York.

[24] Parveen, S., Tiwari, N.K. and Subodh, R. (2017) Estimation and Inter-comparison of Infiltration Models. Water Science, 31, 34-43. https://doi.org/10.1016/j.wsj.2017.03.001

[25] Parveen, S., Tiwari, N.K. and Subodh, R. (2018) Performance Evaluation of Infiltration Models. Journal of Indian Water Resources Society, 38.

[26] Mbagwu, J.S.C. (1990) Mulch and Tillage Effects on Water Transmission Characteristics of an Ultisol and Maize Grain Yield in SE. Nigeria. Pédologie, 40, 155-168.

[27] Machiwal, D., Madan, K.J. and Mal, B.C. (2006) Modelling Infiltration and Quantifying Spatial Soil Variability in a Watershed of Kharagpur, India. Biosystems Engineering, 95, 569-582. https://doi.org/10.1016/j.biosystemseng.2006.08.007

[28] Haghighi-Fashi, F. Sharifi, F. and Kamali, K. (2014) Modelling Infiltration And Geostatistical Analysis of Spatial Variability of Sorptivity and Transmissivity in a Flood Spreading Area. Spanish Journal of Agricultural Research, 12, 277-288.

https://doi.org/10.5424/sjar/2014121-4659 